\title{
Phosphorylated-p38 mitogen-activated protein kinase expression is associated with clinical factors in invasive breast cancer
}

\author{
Bin Wang ${ }^{1 \dagger}$, Huayong Jiang ${ }^{2 \dagger}$, Ning $\mathrm{Ma}^{3 \dagger}$ and Yajie Wang ${ }^{1 *}$
}

\begin{abstract}
Purpose: P38 mitogen-activated protein kinases (MAPK) level is an important prognostic factor in breast cancer. This study was performed to detect the expressions of P-p38 MAPK expression in breast cancer and explore their correlations with clinicopathological factors.

Experimental design: Tumor samples from 355 Chinese patients diagnosed with invasive breast cancer and adjacent non-cancerous tissue were collected between 2003 and 2010. The expression of P-p38 MAPK was analyzed using immunohistochemical staining. The correlations between P-p38 MAPK expression and clinicopathological findings including age, AJCC Stage, Histologic characters, ER, PR, and HER2 were analyzed using the parametric correlation method. P-p38 MAPK was selected as dependent variable to perform multivariate analysis respectively at last.

Results: Overall, 161 (45 \%) and 183 (52\%) of the 355 specimens showed positive P-p38 MAPK staining in the cytoplasm and nucleus respectively, which were significant higher than that in the adjacent non-cancerous tissues in both the cytoplasm and the nucleus. High P-p38 MAPK expression of cytoplasm and nucleus were both associated with positive PR status in luminal A/B type of breast cancer, and were both associated with positive HER2 status in HER2positive type of breast cancer. The result of multivariate analysis demonstrated that HER2 and PR were both significantly association with P-p38 MAPK expression of cytoplasm and nucleus.
\end{abstract}

Conclusions: Our study suggests that P-p38 MAPK expression were significantly associated with clinicopathological factors and PR/HER2 might association with phosphorylation of p38 MAPK in different types of breast cancer.

Keywords: Phosphorylate, p38 MAPK, Invasive, Breast cancer

\section{Background}

According to the May Clinic, breast cancer is the second most common cancer after skin cancer in women in the United States and the most frequently diagnosed malignancy among women worldwide (incidence, approximately 1.38 million per year) that results in 46 million deaths (Lee et al. 2014; Jemal et al. 2011). Activation of mitogen-activated protein kinases (MAPK) is one of the most important intracellular signal transduction

\footnotetext{
*Correspondence: yjwang100@163.com

${ }^{\dagger}$ Bin Wang, Huayong Jiang, and Ning Ma have contributed equally to this work

${ }^{1}$ Department of Oncology, Changhai Hospital, Second Military Medical University, 168, Changhai Road, Shanghai 200433, China

Full list of author information is available at the end of the article
}

pathways in breast carcinoma progression (Blenis 1993; Crews and Erikson 1993).

The MAPK family includes extracellular signal-regulated kinase (ERK), c-Jun N-terminal kinase (JNK), and P38 MAPK (Lei et al. 2014). As a member of the MAPK family, P38 MAPK has been identified as the critical point for a normal immune and inflammatory response as the point of convergence of intracellular downstream growth factor receptor signaling (Cuenda and Rousseau 2007) and the level of them is reportedly associated with advanced stage and short survival in cancers of the breast (Esteva et al. 2004), prostate (Park et al. 2003; Khandrika et al. 2009), bladder (Kumar et al. 2010), liver (Iyoda et al. 2003), and lung (Greenberg et al. 2002; Koul et al. 2013). Activation of P38 MAPK could result in induction of 
gene expression, leading to increased proliferation, invasion, and metastasis in solid cancer (Koul et al. 2013; Mo et al. 2012) and endogenous p38 MAPK activity also reportedly correlates well with breast carcinoma cell invasiveness (Huang et al. 2000; Tang and Han 2013).

The activated form of p38 MAPK, phosphorylation of p38 MAPK (P-p38 MAPK) has been reported in response to ultraviolet irradiation, biologic inducers (e.g., growth factors and cytokines), and chemicals (Dérijard et al. 1994). Levels of P-p38 MAPK have been reported to elevate in breast cancer cells and may be associated with poor overall survival (OS) in patients with lymph node-positive breast carcinoma with adjuvant chemotherapy while location of P-p38 MAPK was not mentioned (Esteva et al. 2001, 2004). Davidsone et al. (2006) also showed that a higher p38 activation ratio correlated with shorter OS in a total of 19 cases. Even so, the expression of P-p38 MAPK in breast cancer and the associated with clinical factors were still not well studied due to a lack of sufficient data.

Based on a total of 355 patients with primary invasive breast carcinoma, the primary goal of the current study was to explore the prevalence of P-p38 MAPK expression and their possible roles in breast cancer. Our observation might direct further investigation on the functions of P-p38 MAPK and influence factor of its expression so as to guide the treatment of invasive breast cancers in future.

\section{Methods}

\section{Ethics statement}

All of the specimens used in this study were used after each patient provided written informed consent. The Ethics Committee of Changhai Hospital granted study approval. The authors confirm that necessary consent was obtained from every patient involved in this study for both participation and publication.

\section{Study population}

Specimens of patients who were diagnosed with primary invasive breast cancer and underwent a surgical procedure between January 2003 and December 2010 at the First Affiliated Hospital of Second Military Medical University (Changhai Hospital, Shanghai, China) were evaluated. Each tumor was classified according to the tumor-node-metastasis (TNM) classification [American Joint Committee on Cancer (AJCC) stage]. Patient age at diagnosis, menopausal status, largest tumor diameter, number of lymph node metastases, TNM stage (AJCC), histological type, and histology grade (Elston-Ellis grade) were recorded with ER, PR, and HER2 expressions. All of the included patients were treated according to National Comprehensive Cancer Network guidelines, which recommend the use of anthracycline-based regimens or anthracycline + taxane-based regimens according to lymph node metastasis status. Anti-hormone and antiHER2 therapy for patients was used according to ER and HER2 expression status.

Among those cases, patients with stage IV disease, a non-curative resection, or another primary tumor site and those who received preoperative radiotherapy or chemotherapy were excluded. Patients who were not treated according to these guidelines were also excluded. We ultimately included a total of 300 patients with invasive breast cancer in this study. The median patient age was 53 (range 31-84) years, while the median OS was 56 (range 3-115) months.

\section{Tissue microarray and immunohistochemistry}

Paraffin-embedded pathological specimens were obtained from the surgically resected tissues. All of these resection samples were treated with a standard fixation, dissection, and processing protocol. In addition, 300 pericarcinoma tissue samples were collected as a control group.

To examine the typical pathological changes, a large tissue microarray (TMA) was used. TMA blocks were constructed using a tissue arraying instrument (Beecher Instruments, Sun Prairie, WI, USA). Cylinders (1.5 mm in diameter) of representative areas of a tissue block were punched from the center of the tumor away from the areas of ulceration and necrosis and re-embedded in a defined position within a recipient paraffin block. The TMA blocks were then cut into 4-mm sections and processed for immunohistochemistry (IHC).

After being washed with phosphate-buffered saline, the specimens were incubated with the primary antibody using ER antibody (dilution 1:50), PR antibody (dilution 1:50), HER2 antibody (dilution 1:50), and P-p38 MAPK antibody (dilution 1:40; Cell Signaling Technology Inc. Boston, USA). Immunostaining was conducted using the Envision System with diaminobenzidine (Dako, Glostrup, Denmark). A negative control was obtained by replacing the primary antibody with normal murine or rabbit immunoglobulin $\mathrm{G}$ with the same dilution.

\section{IHC evaluation}

The P-p38 MAPK expressions in the TMA were independently evaluated by three individuals (Bin Wang, Huayong Jiang, and Ning Ma) who were blinded to the patients' clinicopathological data. Discrepancies were resolved by consensus among the three evaluators.

A positive HER2 result was determined by IHC staining of $3+$ or of $2+$ with a positive fluorescent in situ hybridization result. P-p38 MAPK, ER, and PR receptors were all graded by the three independent observers using 
a four-point scale on which $0=$ no staining, $1+=$ light staining, $2+=$ moderate staining, and $3+=$ strong staining (Leake et al. 2000; Mohammed et al. 2012). Slices with a score of $1+$ were classified as having "low expression," those with $2+$ as "high expression," and those with $3+$ as "overexpression" ("positive") in contrast to slices with a score of 0 , which were classified as having "no expression" ("negative").

\section{Statistical analysis}

The correlation analysis was used to find the possible association between P-p38 MAPK expression and the clinicopathological parameters. The Mann-Whitney U test was used to analyze the correlation between P-p38 MAPK expression and patient age. Kaplan-Meier curves were plotted to assess the effect of P-p38 MAPK expression on OS. Different survival curves were compared using the log-rank test. Multivariate proportional Cox models were used to assess the prognostic significance of P-p38 MAPK expression, age, tumor stage, histological type, and HER2, ER, and PR expressions. $P$ values $\leq 0.05$ were considered significant. The statistical analysis was performed using SPSS19.0 software (SPSS, Inc.).

\section{Results}

\section{Staining of P-p38 MAPK in breast cancers}

P-p38 MAPK was expressed in the cytoplasm and nucleus but not in the membrane (Fig. 1). The expression level of P-p38 MAPK in the cytoplasm and nucleus were both calculated. Of all 355 cases, positive P-p38 MAPK staining was seen in the cytoplasm of 161 (45\%) and in the nucleus of 183 (52\%) ( $P=0.421$ between them). P-p38 MAPK expression levels in the cytoplasm and nucleus were both compared between in tumor tissues and adjacent non-cancerous tissues. Positive P-p38 MAPK staining was found in the cytoplasm in 115 (32\%) and in the nucleus in 133 (37\%) of all examined pericarcinoma tissue samples. P-p38 MAPK expression was higher in the tumor tissues than that in the adjacent noncancerous tissues in both the cytoplasm and the nucleus $(P<0.001$ and $<0.001$, respectively; Table 1$)$.

\section{Association between P-p38 MAPK expression and clinicopathological parameters}

The correlation between P-p38 MAPK expression and clinicopathological parameters was also examined to further elucidate its prognostic value in invasive breast cancer. We found a significant correlation between P-p38 MAPK expression and lymph node metastasis status and AJCC stage in the cytoplasm and nucleus $(P=0.012$ and 0.028 for lymph node metastasis status, and $P=0.032$ and 0.047 for AJCC stage respectively) but not between P-p38 MAPK expression and age, menopause status, depth of invasion, histological classification and histological type $(P>0.05$; Table 2$)$.

\section{Association between P-p38 MAPK expression and ER, PR, or HER2 expression}

ER, PR and HER2 are the four well-known critical factors in breast cancer that guide its clinical treatment and prognosis. What is interesting that upon analyzing the association between P-p38 MAPK and ER, PR and HER2 expression in overall breast cancer, we found the positive correlation between P-p38 MAPK in nucleus and PR $(P=0.000, \mathrm{R}=0.171)$, while did not found any positive correlation thing between P-p38 MAPK and ER, PR or HER2 in cytoplasm (Table 2).

These three parameters mentioned above are also most important in determining the four types of breast cancer types including ER-positive [luminal A subtype, luminal B subtype], HER2-positive subtype, and triple-negative subtype. Then the subtypes of breast cancer were studied one by one. We know that PRs are the products of the connection between estrogen and its receptor. As such, ER-positive breast cancer (luminal A and luminal B) was the focus of our observation. We then attempted to determine the correlation between P-p38 MAPK and PR expression in these two subtypes of breast cancer. Interestingly, we found that this kind of positive correlation did exist both in cytoplasm and in the nucleus $(P=0.001$, $\mathrm{R}=0.220$ in the cytoplasm and $P=0.000, \mathrm{R}=0.225$ in the nucleus) while with $\mathrm{ER}(P=0.025, \mathrm{R}=0.148)$ only in the cytoplasm.

What's more, we also found a positive correlation between P-p38 MAPK expression and HER2 $(P=0.003$, $\mathrm{R}=0.310$ in the cytoplasm and $P=0.013, \mathrm{R}=0.257$ in the nucleus) in HER2-positive subtype. Nothing significant correlation was found in triple-negative breast cancer.

ER+HER2+ luminal B breast cancer was then studied to clarify the correlation between P-p38 MAPK and PR or HER2 at last. As a result, we did find a positive correlation between P-p38 MAPK expression and PR $(P=0.002$, $\mathrm{R}=0.294$ in the cytoplasm and $P=0.001, \mathrm{R}=0.302$ in the nucleus) while not HER2 $(P=0.062, \mathrm{R}=0.185$ in the cytoplasm and $P=0.219, \mathrm{R}=0.121$ in the nucleus).

\section{Multivariate logistic regression analysis}

Because TNM stage was dependent on tumor size and axillary lymph node metastasis, it was excluded in multivariate analysis. Variables that were selected for multivariate analysis included P-p38 MAPK in cytoplasm, P-p38 MAPK in nucleus, HER2, ER, PR, age at diagnosis, menopause, histology grade, histology type, depth of invasion $(\mathrm{T})$, and regional lymph nodes $(\mathrm{N})$. As Table 3 showed, Only PR was demonstrated a significant association with 

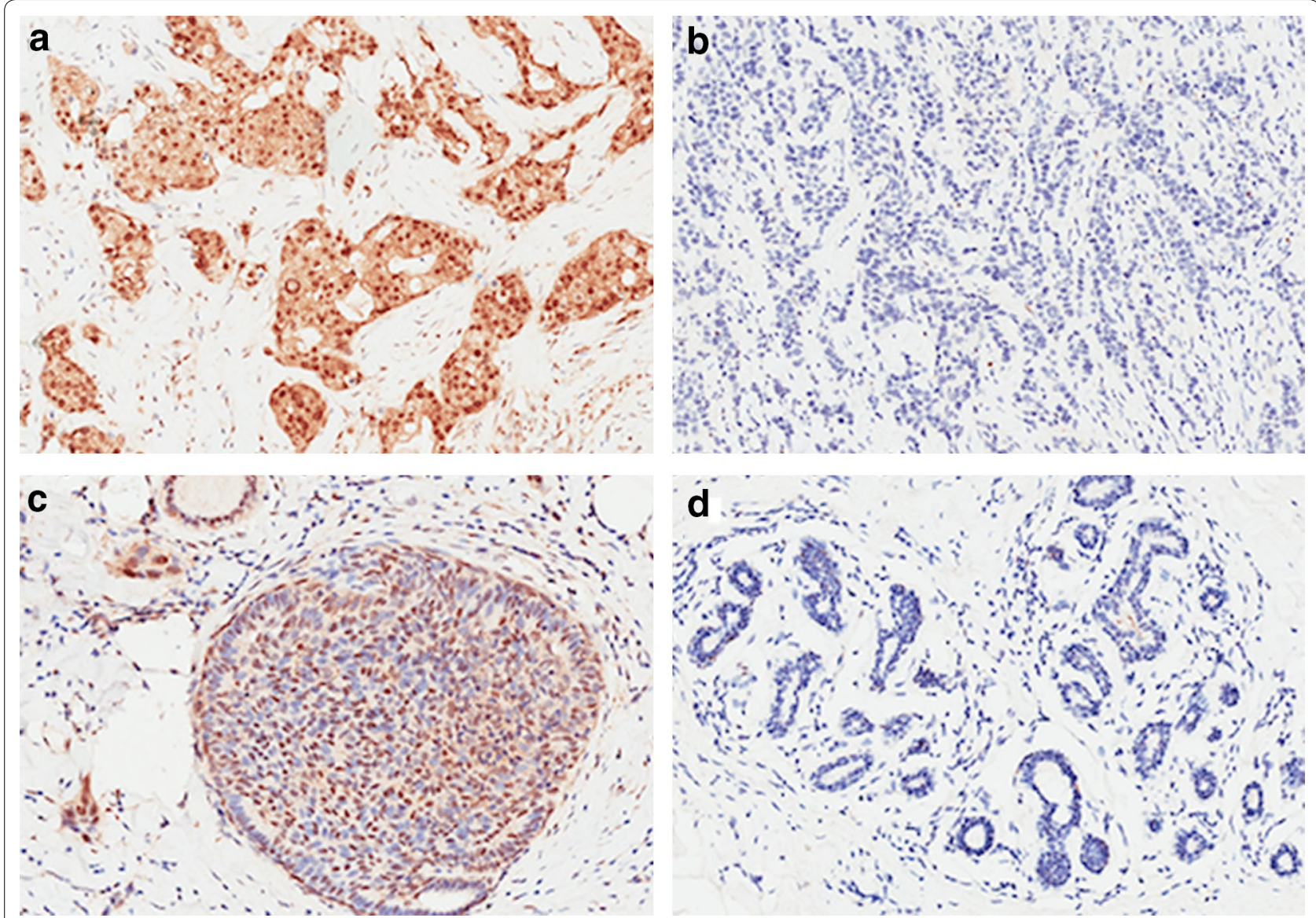

Fig. 1 Representative of breast cancer immunostaining for the P-p38 MAPK in the tumor tissues (a, b) and adjacent non-cancerous tissues (c, d).

a Positive for breast cancer tissues. b Negative for breast cancer tissues. c Positive for adjacent non-cancerous tissues. $\mathbf{d}$ Negative for adjacent noncancerous tissues

Table 1 Diffrence of P-p38 MAPK expression between cancerous tissues and non-cancerous tissues

\begin{tabular}{|c|c|c|c|c|}
\hline & $\mathbf{N}$ & Negative (\%) & Positive (\%) & $P$ \\
\hline \multicolumn{5}{|l|}{ P-p38 MAPK of cytoplasm } \\
\hline Cancerous tissues & 355 & $194(55)$ & $161(45)$ & $<0.001$ \\
\hline Pericarcinoma tissues & 355 & $240(68)$ & $115(32)$ & \\
\hline \multicolumn{5}{|l|}{ P-p38 MAPK of nucleus } \\
\hline Cancerous tissues & 355 & $172(48)$ & $183(52)$ & $<0.001$ \\
\hline Pericarcinoma tissues & 355 & $222(63)$ & $133(37)$ & \\
\hline
\end{tabular}

P-p38 MAPK in cytoplasm and P-p38 MAPK in nucleus in overall breast cancer and PR was also demonstrated the only one which was a significant association in luminal A/B breast cancer. As a result, HER2 was also demonstrated a significant correlated with P-p38 MAPK in HER2-Positive type breast cancer.

\section{Discussion}

In spit of the important role of p38 MAPK as an important prognostic factor in breast cancer, the expression of P-p38 MAPK in breast cancer and the associated with clinical factors remains to be elucidated due to a lack of sufficient data up to now. In the present study, we found that P-p38 MAPK was expressed in both the cytoplasm and nucleus of breast cancer cells and positively correlated with PR expression in those with the luminal A/B subtype while positively correlated with HER2 expression in those with the HER2-positive subtype only in both correlation analysis and multivariate logistic regression analysis.

We know that MKK3, MKK6 and SEK activate p38 MAP kinase by phosphorylation at Thr180 and Tyr182 together. The P-p38 MAPK mAb we chose has been made by Cell Signaling Technology America Inc. to specifically detect endogenous levels of p38 MAPK only when phosphorylated at Thr180 and Tyr182 (www.cellsignal.com). This antibody was used to detect p38 MAPK (including 
Table 2 Correlations between P-p38 MAPK expression and clinicopathologic parameters

\begin{tabular}{|c|c|c|c|c|c|c|c|c|c|c|}
\hline \multirow[t]{3}{*}{ Factors } & \multicolumn{10}{|c|}{ P-p38 MAPK of cytoplasm } \\
\hline & \multirow[t]{2}{*}{ Negative } & \multirow[t]{2}{*}{ Positive } & \multirow[t]{2}{*}{$R$} & \multirow[t]{2}{*}{$P$} & \multicolumn{2}{|c|}{$\begin{array}{l}\text { Luminal } A / B \\
(n=197)\end{array}$} & \multicolumn{2}{|c|}{$\begin{array}{l}\text { HER2-positive } \\
(\mathrm{n}=74)\end{array}$} & \multicolumn{2}{|c|}{$\begin{array}{l}\text { Triple negative } \\
(\mathrm{n}=84)\end{array}$} \\
\hline & & & & & $R$ & $P$ & $R$ & $P$ & $R$ & $P$ \\
\hline \multicolumn{11}{|l|}{ Median age (years) } \\
\hline Median (range) & $53(30-81)$ & $53(31-81)$ & 0.037 & 0.357 & 0.001 & 0.988 & 0.017 & 0.848 & 0.176 & 0.036 \\
\hline \multicolumn{11}{|l|}{ Menopause } \\
\hline Yes & 103 & 90 & 0.002 & 0.687 & -0.039 & 0.558 & -0.018 & 0.87 & 0.19 & 0.058 \\
\hline No & 91 & 71 & & & & & & & & \\
\hline \multicolumn{11}{|l|}{ Depth of invasion } \\
\hline $\mathrm{T} 1$ & 73 & 57 & 0 & 0.999 & 0.042 & 0.517 & -0.063 & 0.543 & -0.03 & 0.759 \\
\hline $\mathrm{T} 2 / \mathrm{T} 3 / \mathrm{T} 4$ & 121 & 104 & & & & & & & & \\
\hline \multicolumn{11}{|c|}{ Regional lymph node metastasis } \\
\hline Negative (N0) & 60 & 93 & 0.016 & 0.72 & 0.027 & 0.662 & 0.026 & 0.795 & -0.024 & 0.807 \\
\hline Positive (N1/N2/N3) & 134 & 68 & & & & & & & & \\
\hline \multicolumn{11}{|l|}{ Stage } \\
\hline । & 60 & 49 & -0.077 & 0.098 & -0.046 & 0.463 & -0.158 & 0.127 & -0.088 & 0.365 \\
\hline$\|/\|$ & 134 & 112 & & & & & & & & \\
\hline \multicolumn{11}{|l|}{ Histologic grade } \\
\hline I & 13 & 10 & -0.034 & 0.474 & 0.003 & 0.961 & -0.204 & 0.057 & -0.067 & 0.5 \\
\hline$\|/\| \|$ & 181 & 151 & & & & & & & & \\
\hline \multicolumn{11}{|l|}{ Histologic type } \\
\hline Ductal & 182 & 148 & 0.009 & 0.85 & -0.041 & 0.533 & 0.147 & 0.173 & -0.011 & 0.912 \\
\hline Lobular & 12 & 13 & & & & & & & & \\
\hline \multicolumn{11}{|l|}{ ER } \\
\hline Negative & 86 & 77 & 0.013 & 0.775 & 0.148 & 0.025 & - & - & - & - \\
\hline Positive & 108 & 84 & & & & & & & & \\
\hline \multicolumn{11}{|l|}{$P R$} \\
\hline Negative & 122 & 93 & 0.083 & 0.078 & 0.22 & 0.001 & - & - & - & - \\
\hline Positive & 72 & 68 & & & & & & & & \\
\hline \multicolumn{11}{|l|}{ Her2 } \\
\hline Negative & 108 & 93 & 0.015 & 0.745 & 0.029 & 0.646 & 0.31 & 0.003 & - & - \\
\hline Positive & 86 & 68 & & & & & & & & \\
\hline \multicolumn{11}{|l|}{ P-p38 MAPK of nucleus } \\
\hline Negative & 163 & 9 & 0.772 & 0.000 & 0.784 & 0.000 & 0.812 & 0.000 & 0.717 & 0.000 \\
\hline Positive & 31 & 152 & & & & & & & & \\
\hline Factors & P-p38 MAPK o & f nucleus & & & & & & & & \\
\hline & Negative & Positive & $R$ & $P$ & $\begin{array}{l}\text { Luminal } A / B \\
(n=197)\end{array}$ & & $\begin{array}{l}\text { HER2-posi } \\
(n=74)\end{array}$ & & $\begin{array}{l}\text { Triple neg } \\
(\mathrm{n}=84)\end{array}$ & tive \\
\hline & & & & & $R$ & $P$ & $R$ & $P$ & $R$ & $P$ \\
\hline Median age (years) & & & & & & & & & & \\
\hline Median (range) & $53(30-59)$ & $53(31-81)$ & 0.028 & 0.479 & 0.012 & 0.817 & 0.037 & 0.684 & 0.099 & 0.234 \\
\hline Menopause & & & & & & & & & & \\
\hline Yes & 95 & 98 & -0.019 & 0.691 & -0.043 & 0.507 & 0.005 & 0.965 & 0.042 & 0.671 \\
\hline No & 77 & 85 & & & & & & & & \\
\hline Depth of invasion & & & & & & & & & & \\
\hline $\mathrm{T} 1$ & 60 & 70 & -0.026 & 0.586 & 0.005 & 0.935 & -0.042 & 0.684 & -0.059 & 0.542 \\
\hline $\mathrm{T} 2 / \mathrm{T} 3 / \mathrm{T} 4$ & 112 & 113 & & & & & & & & \\
\hline Regional lymph node & metastasis & & & & & & & & & \\
\hline
\end{tabular}


Table 2 continued

\begin{tabular}{|c|c|c|c|c|c|c|c|c|c|c|}
\hline \multirow[t]{3}{*}{ Factors } & \multicolumn{10}{|c|}{ P-p38 MAPK of nucleus } \\
\hline & \multirow[t]{2}{*}{ Negative } & \multirow[t]{2}{*}{ Positive } & \multirow[t]{2}{*}{$R$} & \multirow[t]{2}{*}{$P$} & \multicolumn{2}{|c|}{$\begin{array}{l}\text { Luminal A/B } \\
(n=197)\end{array}$} & \multicolumn{2}{|c|}{$\begin{array}{l}\text { HER2-positive } \\
(n=74)\end{array}$} & \multicolumn{2}{|c|}{$\begin{array}{l}\text { Triple negative } \\
(\mathrm{n}=84)\end{array}$} \\
\hline & & & & & $R$ & $P$ & $R$ & $P$ & $R$ & $P$ \\
\hline Negative (N0) & 74 & 79 & -0.019 & 0.68 & -0.033 & 0.584 & 0.045 & 0.653 & -0.031 & 0.747 \\
\hline $\begin{array}{l}\text { Positive (N1/N2/ } \\
\text { N3) }\end{array}$ & 98 & 104 & & & & & & & & \\
\hline \multicolumn{11}{|l|}{ Stage } \\
\hline । & 49 & 60 & -0.087 & 0.061 & -0.068 & 0.272 & -0.108 & 0.295 & -0.129 & 0.182 \\
\hline$\|/\| \|$ & 123 & 123 & & & & & & & & \\
\hline \multicolumn{11}{|l|}{ Histologic grade } \\
\hline । & 10 & 13 & -0.092 & 0.05 & -0.052 & 0.408 & -0.135 & 0.21 & -0.143 & 0.148 \\
\hline$\|/\| \|$ & 162 & 170 & & & & & & & & \\
\hline \multicolumn{11}{|l|}{ Histologic type } \\
\hline Ductal & 160 & 170 & -0.005 & 0.924 & -0.063 & 0.333 & 0.212 & 0.05 & -0.073 & 0.462 \\
\hline Lobular & 12 & 13 & & & & & & & & \\
\hline \multicolumn{11}{|l|}{ ER } \\
\hline Negative & 82 & 81 & 0.07 & 0.127 & 0.122 & 0.053 & - & - & - & - \\
\hline Positive & 90 & 102 & & & & & & & & \\
\hline \multicolumn{11}{|l|}{$P R$} \\
\hline Negative & 116 & 99 & 0.171 & 0.000 & 0.225 & 0.000 & - & - & - & - \\
\hline Positive & 56 & 84 & & & & & & & & \\
\hline \multicolumn{11}{|l|}{ Her2 } \\
\hline Negative & & & -0.006 & 0.894 & -0.018 & 0.771 & 0.257 & 0.013 & - & - \\
\hline Positive & 82 & 72 & & & & & & & & \\
\hline \multicolumn{11}{|c|}{ P-p38 MAPK of nucleus } \\
\hline Negative & & & - & - & 0.784 & 0.000 & 0.812 & 0.003 & 0.727 & 0.000 \\
\hline Positive & - & - & & & & & & & & \\
\hline
\end{tabular}

p38 $\alpha, \beta, \gamma$ and $\delta$ ) peculiarly and does not cross-react with (Cuenda and Rousseau 2007). Consist with this, our

Table 3 Multivariate analysis by logistic regression analysis

\begin{tabular}{|c|c|c|c|c|c|c|}
\hline Breast cancer & Dependent variable & Independent variable & SE & $P$ value & OR & $95 \% \mathrm{Cl}$ \\
\hline \multirow[t]{2}{*}{ Overall } & P-p38 MAPK of cytoplasm & PR & 0.234 & 0.008 & 1.866 & $1.178-2.954$ \\
\hline & P-p38 MAPK of nucleus & PR & 0.246 & 0 & 2.469 & $1.524-3.999$ \\
\hline \multirow[t]{2}{*}{ Luminal A/B } & P-p38 MAPK of cytoplasm & $P R$ & 0.292 & 0.008 & 2.172 & $1.225-3.851$ \\
\hline & P-p38 MAPK of nucleus & $P R$ & 0.308 & 0 & 2.952 & $1.615-5.97$ \\
\hline \multirow[t]{2}{*}{ HER2-positive } & P-p38 MAPK of cytoplasm & HER2 & 0.294 & 0.009 & 2.145 & $1.206-3.816$ \\
\hline & P-p38 MAPK of nucleus & HER2 & 0.287 & 0.03 & 1.868 & $1.063-3.281$ \\
\hline Triple negative & P-p38 MAPK of cytoplasm/nucleus & None & - & - & - & - \\
\hline
\end{tabular}

the phosphorylated forms of either p42/44 MAPK or SAPK/JNK (Kuroyanagi et al. 2015; Kanno et al. 2005). So our results are based on p38 MAP kinase, including the four subtypes mentioned above, and not a single one of them.

P38 MAPK have been shown to be present in both the nucleus and the cytoplasm of quiescent cells before study showed that P-p38 MAPK was expressed not only in the cytoplasm but also in nucleus of breast cancer cells and showed a strongly positive correlation between the expression in cytoplasm and in nucleus (Table 1). Upon cell stimulation, some evidence suggests that p38 MAPK translocates from the cytoplasm to the nucleus (Raingeaud et al. 1995) after phosphorylation while other data 
are consistent with activation of p38 within the nucleus followed by its movement to the cytoplasm. Generally, the different locations maybe imply their different functions. As such, the exact function of P-p38 MAPK in cytoplasm and nucleus in breast cancer should be gone further study in future.

The aim of our study was to clarify the correlation between P-p38 MAPK expression and clinicopathological parameters through correlation analysis and to further explore possible factors affecting its expression through multivariate logistic regression analysis.

The p38 MAPK signaling pathway plays an important role in breast cancer invasion and metastasis (Han et al. 2007; del Barco and Nebreda 2012). In our study, we found that, none of the various clinicopathological parameters, such as age, menopause status, depth of invasion, histological classification, regional lymph node metastasis, histological type, lymph node metastasis and AJCC stage status, was significantly correlated with P-p38 MAPK expression (Table 2).

Our study also showed that PR was the only one that was positively correlated with P-p38 MAPK in cytoplasm, but not in nucleus, among the three critical factors, ER, PR and HER2 in overall data. As the products of the connection between estrogen and its receptor, PRs only appear in ER+ breast cancer (luminal A/B subtype), as expected, this kind of positive correlation existed only in patients with luminal A/B subtype. PR was also demonstrated the only one which was a significant association in luminal A/B breast cancer in multivariate logistic regression analysis. As members of the steroid hormone receptor family, PRs are able to interact with and activate p38 MAP kinase function as part of signaling cascades (Schiff et al. 2004; Dressing et al. 2009) and might play an important role in breast cancer progression via the MAPK signal pathway (Treviño et al. 2013). This is similar to the fact that steroid hormone-induced rapid activation of MAPK appears to be most robust when both ER and PR are coexpressed (Migliaccio et al. 1998; Ballaré et al. 2003). Endocrine therapy in breast cancer aims to disrupt estrogen stimulation of the cancer cells, which are mediated via binding to the ER/PR. Luminal A/B type breast cancers coexpressing ER and PR are generally more sensitive to endocrine therapy than ER alone and perhaps the "more tumoral sensitivity" maybe partly due to lessening the level of P-p38MAPK through disrupting the hormone receptor PR.

P38 signaling has been verified to drive trastuzumab resistance and invasiveness in HER2-overexpressing breast cancer. At last, we found a positive correlation between P-p38 MAPK expression and HER2 in HER2positive but not in overall breast cancer, luminal A/B and even in HER2 positive luminal $B$ breast cancer.
As contrary, nothing significant correlation was found between P-p38 MAPK expression and PR in HER2 positive luminal B breast cancer. In one hand, these results might advocate that HER2 could play an important role in expression of P-p38 MAPK, and on the other hand, our results might imply that country to HER2, PR might be more important than HER2 in P-p38 MAPK in breast cancer which is worthy of going further study in future.

A lot of publications in the past have shown that development of tamoxifen resistance during the short-time period of neoadjuvant therapy was accomplished by loss of PR and an increase in HER2, as well as activated p38 MAPK (Gutierrez et al. 2005; Linderholm et al. 2011). Probably the up-regulated expression of HER2, which could induce the phosphorylation of p38 MAPK, could also restrain ER/PR expression in luminal B type (Fan et al. 2015; Daniel et al. 2011). These opposite expression of PR and P-p38 that predominately activated by HER2, might be used to interpret not only our finding, but also endocrine therapy resistance in patients with HER2 positive luminal $B$ breast cancer. Even though, both the exact con-relationship between PR and P-p38 MAPK, and the effects of P-p38 MAPK expression on the progress of breast cancer in PR positive luminal A/B breast cancer are still both worthy of going further study in future. In addition, there are many of other markers that may be correlated with the main prognostic, such as $\mathrm{CD} 44+1$ CD24-/low biomarker (Camerlingo et al. 2014; de Beça et al. 2013), and epidermal growth factor receptor (Cassol et al. 2010), etc. The corelatioship between those markers and P-p38MAPK merits further study in future to explore which one is more effective than the other.

As for the limitation of sample size, larger numbers of patient samples are still required to conclusively determine the biological significance of P-p38 MAPK in patients with invasive breast cancer. Total p38 MAPK also needs to be detected together to show which one is more reliable factor to predict patient survival in future although the active form of p38 MAPK is more really reflect its function than the inactive one in breast cancer.

\section{Conclusions}

P-p38 MAPK was significantly associated with PR in luminal A/B subtype and with HER2 expression in HER2-positive subtype breast cancer. PR/HER2 might association with phosphorylation of p38 MAPK in different subtype breast cancer and further studies will be needed to conform this mechanism. Our study and further mechanism research will not only help us realize the role p38 MAPK play and the infect of PR/HER2 on their phosphorylation, but also could provide more 


\section{effective means to prevent the progress of tumor in breast cancer.}

\section{Abbreviations}

AJCC: American Joint Committee on Cancer; Cl: confidence interval; ER: estrogen receptor; HER2: human epidermal growth factor receptor 2; HR: hazard ratio; $95 \%$ Cl: 95 \% confidence interval; OS: overall survival; PR: progesterone receptor; TNM: tumor-node-metastasis; TMA: tissue microarray; P-p38 MAPK: phosphorylated p38 MAP kinase.

\section{Authors' contributions}

Conception and design: BW, NM, YJ, and YW. Financial support: BW and YW. Collection and interpretation of data (e.g., statistical analysis, biostatistics, computational analysis): BW, YJ, and NM. Writing, review, and/or revision of the manuscript: BW, NM, and YW. All authors read and approved the final manuscript.

\section{Author details}

1 Department of Oncology, Changhai Hospital, Second Military Medica University, 168, Changhai Road, Shanghai 200433, China. ${ }^{2}$ Department of Radiation Oncology, Beijing Military General Hospital, Beijing 100700, China.

${ }^{3}$ Clinical Laboratory, 85th Hospital of PLA, Shanghai 200052, China.

\section{Acknowledgements}

This study was supported in part by grants from the National Natural Science Foundation of China (NSFC) No. 81472479 to Bin Wang, NSFC No. 81102010 to Yajie Wang, and Changhai Hospital 1255 discipline construction projects to Yajie Wang.

\section{Competing interests}

The authors declare that they have no competing interests.

Received: 25 April 2016 Accepted: 21 June 2016

Published online: 30 June 2016

\section{References}

Ballaré C, Uhrig M, Bechtold T, Sancho E, Di Domenico M, Migliaccio A et al (2003) Two domains of the progesterone receptor interact with the estrogen receptor and are required for progesterone activation of the c-Src/ Erk pathway in mammalian cells. Mol Cell Biol 23:1994-2008

Blenis J (1993) Signal transduction via the MAP kinases: proceed at your own RSK. Proc Natl Acad Sci USA 90:5889-5892

Camerlingo R, Ferraro GA, De Francesco F, Romano M, Nicoletti G, Di Bonito Met al (2014) The role of CD44+/CD24-/low biomarker for screening, diagnosis and monitoring of breast cancer. Oncol Rep 31:1127-1132

Cassol L, Silveira Graudenz M, Zelmanowicz A, Cancela A, Werutsky G, Rovere RK et al (2010) Basal-like immunophenotype markers and prognosis in early breast cancer. Tumori 96:966-970

Crews CM, Erikson RL (1993) Extracellular signals and reversible protein phosphorylation: what to Mek of it all. Cell 74:215-217

Cuenda A, Rousseau S (2007) p38 MAP-kinases pathway regulation, function and role in human diseases. Biochim Biophys Acta 1773:1358-1375

Daniel AR, Hagan CR, Lange CA (2011) Progesterone receptor action: defining a role in breast cancer. Expert Rev Endocrinol Metab 6:359-369

Davidson B, Konstantinovsky S, Kleinberg L, Nguyen MT, Bassarova A, Kvalheim $G$ et al (2006) The mitogen-activated protein kinases (MAPK) p38 and JNK are markers of tumor progression in breast carcinoma. Gynecol Oncol 102:453-461

de Beça FF, Caetano P, Gerhard R, Alvarenga CA, Gomes M, Paredes J et a (2013) Cancer stem cells markers CD44, CD24 and ALDH1 in breast cancer special histological types. J Clin Pathol 66:187-191

del Barco Barrantes I, Nebreda AR (2012) Roles of p38 MAPKs in invasion and metastasis. Biochem Soc Trans 40:79-84

Dérijard B, Hibi M, Wu IH, Barrett T, Su B, Deng T et al (1994) JNK1: a protein kinasestimulated by UV light and Ha-Ras that binds and phosphorylates the c-Jun activation domain. Cell 76:1025-1037
Dressing GE, Hagan CR, Knutson TP, Daniel AR, Lange CA (2009) Progesterone receptors act as sensors for mitogenic protein kinases in breast cancer models. Endocr Relat Cancer 16:351-361

Esteva FJ, Hortobagyi GN, Sahin AA, Smith TL, Chin DM, Liang SY et al (2001) Expression of erbB/HER receptors, heregulin and $\mathrm{P} 38$ in primary breast cancer using quantitative immunohistochemistry. Pathol Oncol Res 7:171-177

Esteva FJ, Sahin AA, Smith TL, Yang Y, Pusztai L, Nahta R et al (2004) Prognostic significance of phosphorylated P38 mitogen activated protein kinase and HER-2 expression in lymph node-positive breast carcinoma. Cancer 100:499-506

Fan W, Chang J, Fu P (2015) Endocrine therapy resistance in breast cancer: current status, possible mechanisms and overcoming strategies. Future Med Chem 7:1511-1519

Greenberg AK, Basu S, Hu J, Yie TA, Tchou-Wong KM, Rom WN et al (2002) Selective p38 activation in human non-small cell lung cancer. Am J Respir Cell Mol Biol 26:558-564

Gutierrez MC, Detre S, Johnston S, Mohsin SK, Shou J, Allred DC et al (2005) Molecular changes in tamoxifen-resistant breast cancer: relationship between estrogen receptor, HER-2, and p38 mitogen-activated protein kinase. J Clin Oncol 23:2469-2476

Han YC, Zeng XX, Wang R, Zhao Y, Li BL, Song M (2007) Correlation of p38 mitogen-activated protein kinase signal transduction pathway to uPA expression in breast cancer. Ai Zheng 26:48-53

Huang S, New L, Pan Z, Han J, Nemerow GR (2000) Urokinase plasminogen activator/urokinase-specific surface receptor expression and matrix invasion by breast cancer cells requires constitutive p38alpha mitogenactivated protein kinase activity. J Biol Chem 275:12266-12272

lyoda K, Sasaki Y, Horimoto M, Toyama T, Yakushijin T, Sakakibara M et al (2003) Involvement of the p38 mitogen-activated protein kinase cascade in hepatocellular carcinoma. Cancer 97:3017-3026

Jemal A, Bray F, Center MM, Ferlay J, Ward E, Forman D (2011) Global cancer statistics. CA Cancer J Clin 61:69-90

Kanno Y, Ishisaki A, Yoshida M, Tokuda H, Numata O, Kozawa O (2005) SAPK JNK plays a role in transforming growth factor-beta-induced VEGF synthesis in osteoblasts. Horm Metab Res 37:140-145

Khandrika L, Lieberman R, Koul S, Kumar B, Maroni P, Chandhoke R et al (2009) Hypoxia-associated p38 mitogen-activated protein kinase-mediated androgen receptor activation and increased HIF-1alpha levels contribute to emergence of an aggressive phenotype in prostate cancer. Oncogene 28:1248-1260

Koul HK, Pal M, Koul S (2013) Role of p38 MAP kinase signal transduction in solid tumors. Genes Cancer 4:342-359

Kumar B, Koul S, Petersen J, Khandrika L, Hwa JS, Meacham RB et al (2010) p38 mitogenactivated protein kinase-driven MAPKAPK2 regulates invasion of bladder cancer by modulation of MMP-2 and MMP-9 activity. Cancer Res 70:832-841

Kuroyanagi G, Otsuka T, Yamamoto N, Matsushima-Nishiwaki R, Kozawa O, Tokuda H (2015) Resveratrol suppresses TGF- $\beta$-induced VEGF synthesis in osteoblasts: inhibition of the p44/p42 MAPKs and SAPK/JNK pathways. Exp Ther Med 9:2303-2310

Leake R, Barnes D, Pinder S, Ellis I, Anderson L, Anderson T et al (2000) Immunohistochemical detection of steroid receptors in breast cancer: a work ing protocol. UK Receptor Group, UK NEQAS, The Scottish Breast Cancer Pathology Group, and The Receptor and Biomarker Study Group of the EORTC. J Clin Pathol 53:634-635

Lee H, Li JY, Fan JH, Li J, Huang R, Zhang BN et al (2014) Risk factors for breast cancer among Chinese women: a 10-year nationwide multicenter crosssectional study. J Epidemiol 24:67-76

Lei YY, Wang WJ, Mei JH, Wang CL (2014) Mitogen-activated protein kinase signal transduction in solid tumors. Asian Pac J Cancer Prev 15:8539-8548

Linderholm BK, Hellborg H, Johansson U, Skoog L, Lehtiö J (2011) Vascular endothelial growth factor receptor 2 and downstream p38 mitogenactivated protein kinase are possible candidate markers of intrinsic resistance to adjuvant endocrine treatment in steroid receptor positive breast cancer. Breast Cancer Res Treat 125:457-465

Migliaccio A, Piccolo D, Castoria G, Di Domenico M, Bilancio A, Lombardi M et al (1998) Activation of the Src/p21 ras/Erk pathway by progesterone receptor via cross-talk with estrogen receptor. EMBO J 17:2008-2018

Mo N, Li ZQ, Li J, Cao YD (2012) Curcumin inhibits TGF- $\beta 1$-induced MMP-9 and invasion through ERK and Smad signaling in breast cancer MDA-MB-231 cells. Asian Pac J Cancer Prev 13.5709-5714 
Mohammed ZM, Edwards J, Orange C, Mallon E, Doughty JC, McMillan DC et al (2012) Breast cancer outcomes by steroid hormone receptor status assessed visually and by computer image analysis. Histopathology 61:283-292

Park Jl, Lee MG, Cho K, Park BJ, Chae KS, Byun DS et al (2003) Transforming growth factor-beta1 activates interleukin-6 expression in prostate cancer cells through the synergistic collaboration of the Smad2, p38-NFkappaB, JNK, and Ras signaling pathways. Oncogene 22:4314-4332

Raingeaud J, Gupta S, Rogers JS, Dickens M, Han J, Ulevitch RJ et al (1995) Proinflammatory cytokines and environmental stress cause p38 mitogenactivated protein kinase activation by dual phosphorylation on tyrosine and threonine. J Biol Chem 270:7420-7426
Schiff R, Massarweh SA, Shou J, Bharwani L, Mohsin SK, Osborne CK (2004) Cross-talk between estrogen receptor and growth factor pathways as a molecular target for overcoming endocrine resistance. Clin Cancer Res 10:331S-336S

Tang L, Han X (2013) The urokinase plasminogen activator system in breast cancer invasion and metastasis. Biomed Pharmacother 67:179-182

Treviño LS, Bingman WE 3rd, Edwards DP, NI W (2013) The requirement for p42/p44 MAPK activity in progesterone receptor-mediated gene regulation is target gene-specific. Steroids 78:542-547

\section{Submit your manuscript to a SpringerOpen ${ }^{\circ}$ journal and benefit from:}

- Convenient online submission

- Rigorous peer review

- Immediate publication on acceptance

- Open access: articles freely available online

- High visibility within the field

- Retaining the copyright to your article 